\title{
Health management of patients with COVID-19: is there a room for hydrotherapeutic approaches?
}

\author{
Mélina Bailly ${ }^{1}(1) \cdot$ Bertrand Evrard $^{2,3} \cdot$ Emmanuel Coudeyre $^{4} \cdot$ Corinne Rochette $^{5} \cdot$ Laurent Meriade $^{5}$. \\ Christelle Blavignac $^{6} \cdot$ Anne-Cécile Fournier $^{7} \cdot$ Yves-Jean Bignon $^{8,9} \cdot$ Frédéric Dutheil $^{10} \cdot$ Martine Duclos $^{11}$. \\ David Thivel $^{1}$
}

Received: 4 November 2021 / Revised: 18 January 2022 / Accepted: 19 January 2022 / Published online: 25 January 2022

(c) The Author(s) under exclusive licence to International Society of Biometeorology 2022

\begin{abstract}
With highly variable types of coronavirus disease 2019 (COVID-19) symptoms in both severity and duration, there is today an important need for early, individualized, and multidisciplinary strategies of rehabilitation. Some patients present persistent affections of the respiratory function, digestive system, cardiovascular function, locomotor system, mental health, sleep, nervous system, immune system, taste, smell, metabolism, inflammation, and skin. In this context, we highlight here that hydrothermal centers should be considered today as medically and economically relevant alternatives to face the urgent need for interventions among COVID-19 patients. We raise the potential benefits of hydrotherapy programs already existing which combine alternative medicine with respiratory care, physical activity, nutritional advice, psychological support, and physiotherapy, in relaxing environments and under medical supervision. Beyond the virtues of thermal waters, many studies reported medical benefits of natural mineral waters through compressing, buoyancy, resistance, temperature changes, hydrostatic pressure, inhalations, or drinking. Thermal institutions might offer individualized follow-up helping to unclog hospitals while ensuring the continuity of health care for the different clinical manifestations of COVID-19 in both post-acute and chronic COVID-19 patients. Our present review underlines the need to further explore the medical effectiveness, clinical and territorial feasibility, and medico-economic impacts of the implementation of post-COVID-19 patient management in hydrotherapeutic establishments.
\end{abstract}

Keywords COVID-19 $\cdot$ SARS-CoV-2 $\cdot$ Hydrotherapy $\cdot$ Alternative medicine $\cdot$ Thermal waters

\section{COVID-19: an ongoing global pandemic}

In November 2019, one of the most complex pandemics to control was breaking out at Wuhan, before spreading across the rest of the world. While all medical units first had to deal with the urgency of the crisis management, after repeated waves of acute infection, arose the difficult problem of post-coronavirus disease 2019 (COVID-19) patient care involving multidisciplinary post-COVID-19 rehabilitations. As of October 20, 2021, the world health organization (WHO) counted more than 241 million confirmed cases of COVID-19 (World Health Organization 2021a), a number that keeps increasing. Health issues related to the Severe Acute Respiratory Syndrome CoronaVirus 2 (SARS-CoV-2)

Mélina Bailly

melina.bailly@uca.fr

Extended author information available on the last page of the article appear highly variable regarding the types of symptoms but also considering its severity and duration (Sun et al. 2020a). With less than 2 years of hindsight, we only have little scientific evidence regarding the long-term consequences of the SARS-CoV-2 infection. Yet, about 10\% of COVID-19 patients present symptoms mainly respiratory, musculoskeletal, or neuropsychiatric not explainable by other causes more than four weeks after the diagnosis of SARS-CoV-2 infection, which can therefore be considered as long-COVID cases (Sisó-Almirall et al. 2021). On October 6, 2021, the WHO announced the first official definition of what can really be considered as long-COVID (World Health Organization 2021b), mentioning that it "occurs in individuals with a history of probable or confirmed SARS-CoV-2 infection, usually 3 months from the onset of COVID-19, with symptoms that last for at least 2 months and cannot be explained by an alternative diagnosis" (World Health Organization 2021b). The definition further states that common symptoms 
may include fatigue, cognitive dysfunction, and several others that can affect daily functioning. In this context, many studies pointed out the urgency to propose early, individualized, and multidisciplinary strategies for the rehabilitation of COVID-19 patients (Sun et al. 2020b).

\section{Both physiological and psychological heterogenous symptoms that may last over time}

While cough, fever, dyspnea, and fatigue appeared as the most common clinical manifestations of SARS-CoV-2 (Sun et al. 2020a; Sisó-Almirall et al. 2021), heterogeneous symptoms and variable severity and duration have been reported (Cabrera Martimbianco et al. 2021). Metabolic, functional, energy but also psycho-cognitive symptoms have been described, and the different systems of the organism can be touched (Bornstein et al. 2020; Steardo et al. 2020; Batabyal et al. 2021; Burtscher et al. 2021). One of the systems that is most frequently and severely altered by the SARS-CoV-2 is the respiratory system, with patients presenting symptoms such as expectorations, dyspnea, or respiratory distress syndrome (Sun et al. 2020a). Indeed, the lungs appear as the organ most affected by the virus and its infection might imply persistent impairments. It had been shown that defects in diffusion capacity followed by restrictive ventilatory impairments are the most common remaining abnormalities of lung capacity (Mo et al. 2020). COVID-19 is also characterized by extensive injury to epithelial and endothelial cells with secondary fibroproliferation (Venkataraman and Frieman 2017) and a potential for chronic vascular and alveolar remodeling which can induce lung fibrosis or pulmonary hypertension (Frija-Masson et al. 2020; Torres-Castro et al. 2021). More than half of the patients present abnormal lung function 30 days after the symptoms onset (Frija-Masson et al. 2020) and the most important pulmonary function test affected would be the diffusion capacity, altered in about $40 \%$ of the post-COVID-19 patients (Torres-Castro et al. 2021). The restrictive ventilatory defects and the small function dysfunction can be persistent and not necessarily related to the COVID-19 severity (You et al. 2020). Digestive symptoms such as nausea, vomiting, diarrhea, and abdominal pain (Wang et al. 2021) are also frequently observed as well as a loss of appetite, ageusia, and anosmia (Lee et al. 2020). Other complications like skin disorders, such as skin rashes, are also sometimes reported (Iwu et al. 2021). In addition to the diversity of the different forms and severities of SARS-CoV-2, complex interactions with already existing comorbidities can interfere. For instance, Jain and Yuan observed in their systematic review that cardiovascular, hypertension, and diabetes also represent predictive symptoms/comorbidities for severe COVID-19 in intensive care unit (ICU) admission (Jain and Yuan 2020).

Beyond these physiological consequences of SARSCoV-2, patients may also develop psychological disorders. Fear, anxiety, stress, depression, anger, but also sleep disorders, and insomnia have been reported (Deng et al. 2021), with further disorders in case of isolation treatment periods or stay in ICU (Sun et al. 2020b). Following the acute phase of COVID-19, a significant proportion of patients still present symptoms for several weeks/months/years after the contraction of the virus. Depending upon the duration of symptoms, post-COVID-19 or long-COVID-19 can be divided into two stages: post-acute COVID-19 where symptoms extend beyond 3 weeks but less than 12 weeks, and chronic-COVID-19 where symptoms extend beyond 12 weeks (Greenhalgh et al. 2020). Based on 25 observational studies including 5440 participants in total, the frequency of long-COVID-19 cases ( 3 to 24 weeks after the acute phase or hospital discharge) would range from 4.7 to $80 \%$ in the included studies (Cabrera Martimbianco et al. 2021). The main subsisting symptoms reported are chest pain, chronic fatigue, dyspnea (lung sequelae or hyperventilation syndromes), cough, sputum production but also sleep disorders, and mental conditions such as depression or anxiety (Iwu et al. 2021; Sisó-Almirall et al. 2021; Cabrera Martimbianco et al. 2021). Diverse other symptoms such as anosmia, dysgeusia, rhinorrhea, diarrhea, vomiting, nausea, abdominal pain, myalgia, arthralgia, sore throat, headache, or chills are also observed in long-COVID-19 cases (Sisó-Almirall et al. 2021). The pathophysiology of postCOVID-19 syndromes remains very debated and certainly depends on the type of symptoms presented by the patient (Nalbandian et al. 2021). The potentially involved mechanisms could be primarily changes directly induced by the virus specifically. Second, varied immunological aberrations have been highlighted. Some forms would be inflammatory with strong activation of the innate immune response, the production of inflammatory cytokines, activation of a procoagulating phenotype, and the induction of cell damage and tissue. Phenomena of self-immunity have sometimes been highlighted. Finally, some forms would be linked to tissue sequelae following acute disease. Currently, it is considered that this pathophysiology is multifactor and also has metabolic abnormalities.

\section{An urgent need for new innovative rehabilitation programs}

Due to both the magnitude and the suddenness of the COVID-19 health crisis, all the different rehabilitation strategies and their effectiveness have not been systematically 
assessed and demonstrated while the literature points out the real need for multidisciplinarity in the recovery process (Sun et al. 2020b; Puchner et al. 2021). There is a high demand for rehabilitation among COVID-19 patients, which requires comprehensive and individualized approaches $(\mathrm{Li}$ et al. 2020). For instance, the potential benefits of physical and mental training of Tai Chi (Zhu et al. 2021) or Yoga (Jenefer Jerrin et al. 2021) on the overall health of COVID-19 patients have been raised. More generally, some programs of rehabilitation for both in- and outpatientsbased on exercise training such as active range of motion exercises in-bed, sit to stand, walking, cycling, gymnastic or strengthening exercises-have already been investigated for recovery of COVID-19 patients (Zampogna et al. 2021; Al Chikhanie et al. 2021; Ozyemisci Taskiran et al. 2021; Rodriguez-Blanco et al. 2021). Such clinical programs might however miss considering the overall spectrum of symptoms experienced by COVID-19 patients. Moreover, they have most of the time a somehow important medico-economic cost, require an important availability of the clinical staff and facilities, and might not be accessible to all the patients living far from clinics and hospitals. Regarding the heterogeneity of COVID-19 symptoms, there is a real need for innovative health strategies with combined approaches for respiratory, functional, digestive, and psychological recovery. Such multidisciplinary approaches remain difficult to develop and implement in our current medico-economic system, in particular with respect to the high prevalence of COVID-19 patients.

\section{What about hydrotherapeutic multidisciplinary approaches ?}

Meanwhile, the interest in and use of alternative care and medicines combining light body motion, respiratory exercises, and a mind-body approach have been growing among COVID-19 patients in the last months. For instance, an impressive number of studies assessing the multiple effects of traditional Chinese medicine (herbal medicine, massage, exercise, acupuncture, dietary therapy) has been published to date (Zhao et al. 2021), either implemented during the acute phase or in the recovery stage. Yet, other types of alternative medicines have also been proposed as innovative rehabilitative treatments, such as health resort medicine that has been suggested as a suitable setting to take care of discharged patients (Masiero et al. 2020a). Since much evidence demonstrated the efficiency of spa environment on several respiratory diseases, spa setting might indeed represent a relevant out-of-hospital alternative (Maccarone and Masiero 2021), especially in the context of an increasing number of patients with respiratory outcomes whereas only a few facilities remain available. As mineral-rich waters were found to improve immune function, the potential benefits of such waters might also be discussed in the era of COVID-19 (Masiero et al. 2020b). In addition, the inexpensive nature of spa therapy would represent a relevant financial strategy in the medico-economic management of the present health crisis (Kardeş 2021). While the pandemic crisis and the consecutive lockdowns distancing restrictions have critically affected their activity, hydrothermal centers should then be considered today as medically and economically pertinent alternatives to face the urgent need for interventions among COVID-19 patients (Masiero et al. 2020a, b; Maccarone and Masiero 2021; Kardeş 2021). Indeed, beyond the virtues of thermal waters, thermal institutions present several multidisciplinary health care programs combining alternative medicine with respiratory care, adapted physical activity programs, nutritional support, psychological support, physiotherapy, massage, music, or aromatherapy, in relaxing environments and under medical supervision.

\section{Benefits of natural mineral waters}

Water-based therapies are century-old practices that have been recognized for their regenerative properties increasing the natural body's ability to heal (Gianfaldoni et al. 2017). Hydrotherapy is a generic word referring to the use of water in any form, either internally or externally, as a therapy for health purposes and may combine various types of approaches using natural mineral waters such as compressing, counterbalance to gravity (buoyancy), resistance, thermal conduction (cold, body temperature, hot), hydrostatic pressure, inhalations, or drinking of natural mineral waters. Scientific evidence-based thermal, mechanical, and chemical effects have been reported on various systems of the body (Mooventhan and Nivethitha 2014). Among therapies daily used by thermal centers, many of them match the post-COVID-19 sequellae. For instance, Zajac recently proposed an interesting review on the use of inhalations with natural mineral waters in the therapy of respiratory airway disorders and she concluded that this kind of approach was beneficial for almost all manifestations of respiratory diseases, probably relying on the restoration of the proper defense mechanisms of the body (Zajac 2021). Anti-inflammatory effects of thermal waters inhalations are indeed observed in different pulmonary affections such as those observed due to chronic obstructive pulmonary disease (COPD) (Pellegrini et al. 2005) or high tobacco consumption (Carubbi et al. 2019), with specific impacts on the metabolic respiratory parameters and could thus be particularly suitable for directly opposing the physiopathological data of post-COVID-19 syndromes as described above. 


\section{A specific interest for hydrogen sulfide application ?}

Regarding both the prevention and treatment of SARSCoV-2, potential benefits of hydrogen sulfide $\left(\mathrm{H}_{2} \mathrm{~S}\right)$ naturally found in some natural mineral waters have been described (Evgen'ev and Frenkel 2020; Pozzi et al. 2021). Recognized as a strong biological mediator with antioxidant and anti-inflammatory effects, $\mathrm{H}_{2} \mathrm{~S}$ was also found to provide a significant antiviral activity against a broad range of emerging enveloped RNA viruses (Bazhanov et al. 2017). Recently, $\mathrm{H}_{2} \mathrm{~S}$ was shown to significantly reduce the transmembrane protease serine 2 (TMPRSS2), one of the two main host proteins implicated in the cell entry of SARS-CoV-2 (Pozzi et al. 2021). These new findings, therefore, raise new interests for $\mathrm{H}_{2} \mathrm{~S}$-rich inhalational treatment in the prevention of SARS-CoV-2 infection or second reinfection, by preventing the virus from spreading into the lower respiratory tract and the lungs (Pozzi et al. 2021). Some well-documented hypotheses also suggest that $\mathrm{H}_{2} \mathrm{~S}$ might have an inhibitory effect on SARS-CoV-2 replication in addition to the possibility of interrupting viral entry (Yang 2020). Since $\mathrm{H}_{2} \mathrm{~S}$ has the property to reverse lung inflammation and improve pulmonary function in various models of lung injury (Tang et al. 2017; Ali et al. 2018), Yang also suggests its potential benefit on lung damage caused by SARS-CoV-2 infection (Yang 2020). Biological mechanisms explaining how thermal water-associated $\mathrm{H}_{2} \mathrm{~S}$ modulate clinical improvements on human airways and associated immune cells have indeed been explored in many respiratory diseases (such as allergic rhinitis, asthma, and COPD) (Viegas et al. 2019). Sulfurous thermal waters would not only provide antioxidant, anti-inflammatory, and antiviral properties, but also mucolytic, analgesic, antiproliferative, and anticancer properties. This would result in prophylactic and therapeutic beneficial effects, but would also help decreasing socio-economic costs due to fewer hospital admissions and to a reduction of disease-related healthcare charges (Viegas et al. 2019).

\section{Demonstrated benefits of hydrotherapy on human physiology}

More globally, aquatic training is well-known to have a beneficial role on metabolic and neuromuscular systems due to the fundamental principles of hydrodynamics, such as the buoyancy or resistance properties of water (Torres-Ronda and del Alcázar 2014). Indeed, these properties imply low joint impacts which are relevant for osteoarticular and muscular affections, such as those observed in short or long-term hospitalized COVID-19 patients (Sagarra-Romero and Viñas-Barros 2020). Two systematic reviews reported a better quality of life, pain reduction, and functional improvements in patients with osteoarticular affections (Bender et al. 2014; Ma et al. 2021). Beyond the effects on the neuromuscular system, hydrotherapeutic treatments are also well-recognized for many other benefits. For instance, water-based exercise training also improves the health status of patients with COPD (Khaltaev et al. 2020); water immersion promotes sleep quality therefore helping reduce fatigue (An et al. 2019); mineral waters have anti-irritant effects particularly used to relieve skin irritations (Ferreira et al. 2010; Eliasse et al. 2020); and balneotherapy present many benefits for metabolism, inflammation, and antioxidant status (Bender et al. 2014). It has also been reported by an integrative literature review conducted in 2019 that water immersion, independently of any mechanical effects, provides thermal effects on health outcomes (An et al. 2019). For instance, warm water immersion would have specific effects on the cardiovascular system while cold water would have impacts on the neuromuscular system (An et al. 2019).

The benefits of waters might also be due to their chemical composition naturally rich in different minerals and other components (Nguyen Ba 2020). For instance, sodium chloride-rich mineral waters might be beneficial for digestive disorders (Crespo et al. 2021), salty and sulfur waters for dermatological applications (Cacciapuoti et al. 2020), or sulfate mineral waters appear as a medical resource used for several disorders, such as gastroenteric, musculoskeletal, skin, and respiratory disorders (Costantino et al. 2019) — types of symptoms presented by post-COVID-19 patients. Supplementation of mineral water during thermal therapy has been shown to provide digestive benefits in patients with functional dyspepsia or irritable bowel syndrome, with specific improvements on the gastric acid output and transit duration, as well as a reduction of the different other symptoms (Gasbarrini et al. 2006). Interests for hydrotherapy in COVID-19 patients have also recently been raised by Ramirez and collaborators (Ramirez et al. 2021). They urged the need for clinical studies assessing some water properties in the COVID-19 patients and specifically discussed the potential benefits of hydrothermotherapy on the immune system function based on the SARS-CoV-2 vulnerability to heat (Ramirez et al. 2021).

\section{Psychological benefits of water-based therapy}

Importantly, beyond the physiological effects of water-based therapy, psychological benefits can also be observed, such as mental relaxation, mental fatigue recovery, management of 
pain, lower stress, a better quality of life, lower anxiety, and lower depression-dejection scores (Mizuno et al. 2010; Han et al. 2014; Goto et al. 2018), all of them being described in the literature as significantly affected among patients with COVID-19 infection (Steardo et al. 2020; Deng et al. 2021). As displayed in Fig. 1, many symptoms due to COVID-19 infection match the treatments and benefits already provided by thermal centers.

\section{Possible limitations and dangers}

If many potential benefits of balneotherapy in the context of this unprecedented health crisis have been raised here, possible limitations and dangers should also be discussed (Guvener 2020). Indeed, hydrothermal centers are usually warm and humid environments reported to favor the survival and transmission of viruses through the respiratory tract but also by direct or indirect contact, even if the results of some studies remain variable (Guvener 2020). In addition, the social distancing might be difficult to maintain in such promiscuous spaces in which patients, physicians, and staff members are in close contact. The present health context would imply important attention for the equipment disinfection since some of them could be highly favorable to the virus dissemination-such as inhalers for instance. Post-COVID-19 patients are however not supposed to be more contagious than the others (or even less), and thermal spas are already receiving patients with various conditionspatients who do not seem to present higher levels of contamination in the observation of the sanitary recommendations.

\section{A relevant strategy in the health management of the COVID-19 crisis ?}

Considering the specific symptoms observed and described among COVID-19 patients, and looking at the multiple benefits of hydrotherapy in its various approaches on these kinds of symptoms, it appears today relevant to propose and explore its clinical effectiveness. Thermal institutions propose alternative treatments that can offer multidisciplinary individualized interventions and follow-up of patients during recovery while helping to unclog clinics and hospitals. Spa
Fig. 1 Potential benefits of hydrotherapy on symptoms due to Severe Acute Respiratory Syndrome Coronavirus 2 (SARS-CoV-2) infection

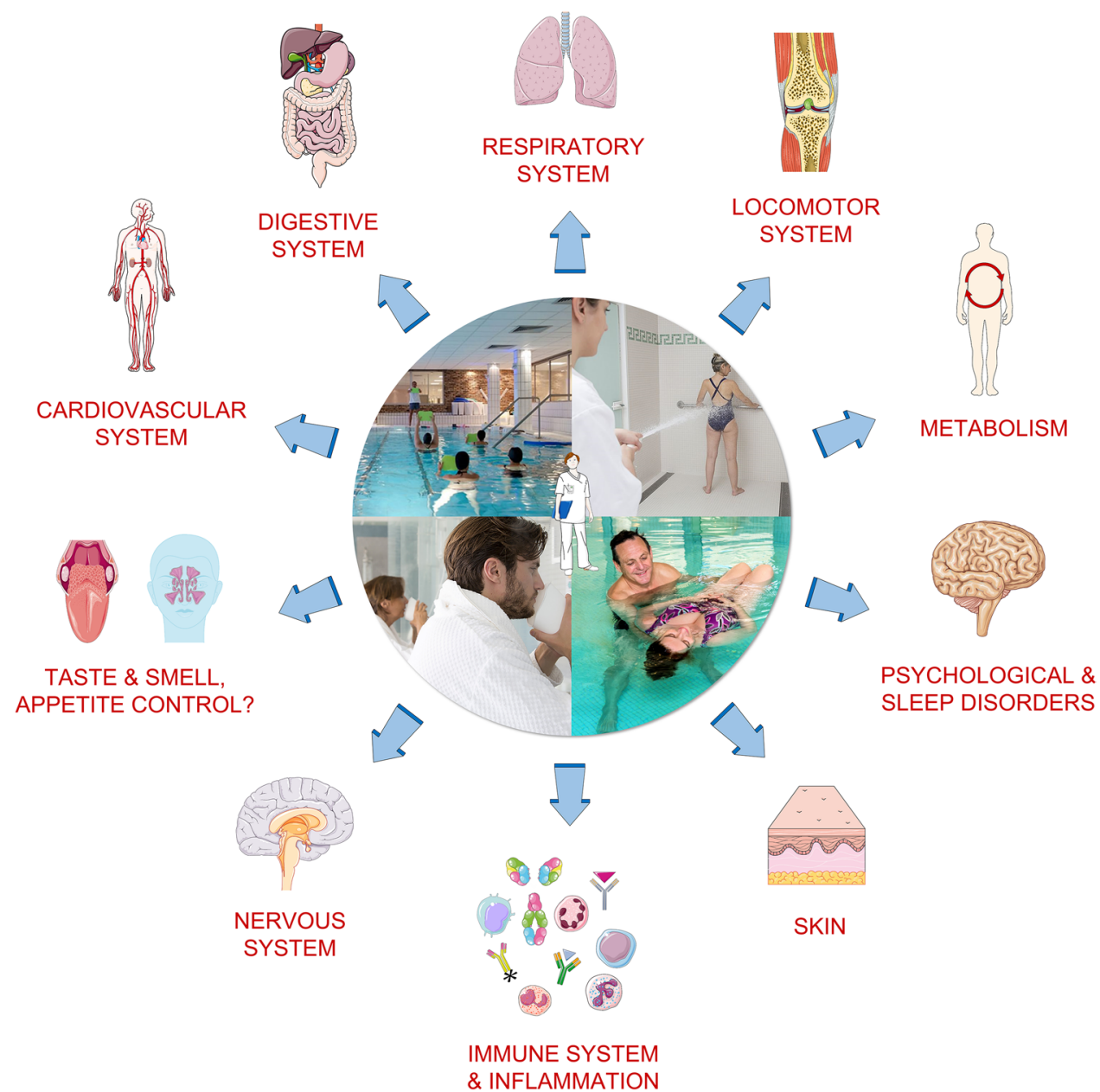


centers and the associated activities in spa town might play a relevant role in the management of the COVID-19 crisis, helping reduce the length of stay in hospital for severe forms and providing adapted strategies for the remaining disorders of long-COVID-19 patients. This complementary therapy using water for health purposes might ensure the continuity of health care within thermal establishments for the different clinical manifestations of the SARS-CoV-2, through combined approaches for respiratory, functional, digestive, and psychological recovery. The integration of care in their territories, particularly in rural areas, is a very current research topic in health management to which significant responses have already been made (Fleury et al. 2017; Gervasi et al. 2020; Mériade and Rochette 2021). Applied to COVID-19 patients and to care in and out of hospitals, it can help define tools and actions adapted to the continuity of care between the institutions concerned. It would therefore appear to be very appropriate today to deepen research aimed at evaluating both the medical effectiveness, clinical and territorial feasibility, and medico-economic impact of the implementation of post-COVID-19 patient management in hydrotherapeutic establishments.

Acknowledgements We thank all the staff (physicians, researchers, and employees related to the European Fund for Regional Development) engaged in the project "Immuno-Metabolic (IM) Phenotyping and management of COVID-19: Specificity of actors and of the Auvergne territory" (CAUVIM-19 project) for their valuable support and investment in this project. We also thank the InnovaTherm Cluster for its support.

Author contribution Conceptualization, supervision, project administration, funding acquisition: D.T., B.E., M.D., M.B., F.D., YJ.B., AC.F., C.B., L.M., C.R., E.C.; methodology; D.T., M.B., validation; formal analysis; investigation; resources, visualization: D.T.; writing—original draft preparation: M.B., D.T.; writing-review and editing: B.E., E.C., C.R., L.M., C.B., YJ.B., M.D. All authors have read and agreed to the published version of the manuscript.

Funding This publication is related to the project named "CAUVIM-19 - Immuno-Metabolic (IM) Phenotyping and management of COVID-19: Specificity of actors and of the Auvergne territory". The "CAUVIM-19" project is co-funded by the FEDER (European Fund for Regional Development) as part of the European Union's response to the COVID-19 pandemic.

\section{Declarations}

Competing interests The authors declare no competing interests.

\section{References}

Al Chikhanie Y, Veale D, Schoeffler M et al (2021) Effectiveness of pulmonary rehabilitation in COVID-19 respiratory failure patients post-ICU. Respir Physiol Neurobiol 287:103639. https://doi.org/ 10.1016/j.resp.2021.103639
Ali FF, Abdel-Hamid HA, Toni ND (2018) H2S attenuates acute lung inflammation induced by administration of lipopolysaccharide in adult male rats. Gen Physiol Biophys. https://doi.org/10.4149/ gpb_2018002

An J, Lee I, Yi Y (2019) The Thermal effects of water immersion on health outcomes: an integrative review. Int J Environ Res Public Health 16:E1280. https://doi.org/10.3390/ijerph16071280

Batabyal R, Freishtat N, Hill E et al (2021) Metabolic dysfunction and immunometabolism in COVID-19 pathophysiology and therapeutics. Int J Obes 45:1163-1169. https://doi.org/10.1038/ s41366-021-00804-7

Bazhanov N, Escaffre O, Freiberg AN et al (2017) Broad-range antiviral activity of hydrogen sulfide against highly pathogenic RNA viruses. Sci Rep 7:41029. https://doi.org/10.1038/srep41029

Bender T, Bálint G, Prohászka Z et al (2014) Evidence-based hydroand balneotherapy in Hungary-a systematic review and metaanalysis. Int J Biometeorol 58:311-323. https://doi.org/10.1007/ s00484-013-0667-6

Bornstein SR, Dalan R, Hopkins D et al (2020) Endocrine and metabolic link to coronavirus infection. Nat Rev Endocrinol 16:297298. https://doi.org/10.1038/s41574-020-0353-9

Burtscher J, Burtscher M, Millet GP (2021) The central role of mitochondrial fitness on antiviral defenses: an advocacy for physical activity during the COVID-19 pandemic. Redox Biol 43:101976. https://doi.org/10.1016/j.redox.2021.101976

Cabrera Martimbianco AL, Pacheco RL, Bagattini ÂM, Riera R (2021) Frequency, signs and symptoms, and criteria adopted for long COVID-19: a systematic review. Int J Clin Pract e14357. https:// doi.org/10.1111/ijcp.14357

Cacciapuoti S, Luciano MA, Megna M et al (2020) The role of thermal water in chronic skin diseases management: a review of the literature. J Clin Med 9:3047. https://doi.org/10.3390/jcm9093047

Carubbi C, Masselli E, Calabrò E et al (2019) Sulphurous thermal water inhalation impacts respiratory metabolic parameters in heavy smokers. Int J Biometeorol 63:1209-1216. https://doi.org/ 10.1007/s00484-019-01737-7

Costantino M, Izzo V, Conti V et al (2019) Sulphate mineral waters: a medical resource in several disorders. J Tradit Complement Med 10:320-326. https://doi.org/10.1016/j.jtcme.2019.04.004

Crespo P-V, Campos F, Leal M, Maraver F (2021) Effects of sodium chloride-rich mineral water on intestinal epithelium. Experimental Study. Int J Environ Res Public Health 18:3261. https://doi.org/ 10.3390/ijerph18063261

Deng J, Zhou F, Hou W et al (2021) The prevalence of depression, anxiety, and sleep disturbances in COVID-19 patients: a metaanalysis. Ann N Y Acad Sci 1486:90-111. https://doi.org/10. 1111/nyas.14506

Eliasse Y, Redoules D, Espinosa E (2020) Impact of Avène Thermal Spring Water on immune cells. J Eur Acad Dermatol Venereol JEADV 34(Suppl 5):21-26. https://doi.org/10.1111/jdv.16335

Evgen'ev MB, Frenkel A (2020) Possible application of H2S-producing compounds in therapy of coronavirus (COVID-19) infection and pneumonia. Cell Stress Chaperones 25:713-715. https://doi.org/ 10.1007/s12192-020-01120-1

Ferreira MO, Costa PC, Bahia MF (2010) Effect of São Pedro do Sul thermal water on skin irritation. Int J Cosmet Sci 32:205-210. https://doi.org/10.1111/j.1468-2494.2010.00527.x

Fleury M-J, Grenier G, Vallée C et al (2017) Implementation of Integrated Service Networks under the Quebec Mental Health Reform: Facilitators and Barriers associated with Different Territorial Profiles. Int J Integr Care 17:3. https://doi.org/10.5334/ ijic. 2482

Frija-Masson J, Debray M-P, Gilbert M et al (2020) Functional characteristics of patients with SARS-CoV-2 pneumonia at 30 days post-infection. Eur Respir J 56:2001754. https://doi.org/10.1183/ 13993003.01754-2020 
Gasbarrini G, Candelli M, Graziosetto RG et al (2006) Evaluation of thermal water in patients with functional dyspepsia and irritable bowel syndrome accompanying constipation. World J Gastroenterol WJG 12:2556-2562. https://doi.org/10.3748/wjg.v12.i16. 2556

Gervasi G, Bellomo G, Mayer F et al (2020) Integrated care pathways on dementia in Italy: a survey testing the compliance with a national guidance. Neurol Sci off J Ital Neurol Soc Ital Soc Clin Neurophysiol 41:917-924. https://doi.org/10.1007/ s10072-019-04184-9

Gianfaldoni S, Tchernev G, Wollina U et al (2017) History of the baths and thermal medicine. Open Access Maced J Med Sci 5:566-568. https://doi.org/10.3889/oamjms.2017.126

Goto Y, Hayasaka S, Kurihara S, Nakamura Y (2018) Physical and Mental effects of bathing: a randomized intervention study. EvidBased Complement Altern Med ECAM 2018:9521086. https:// doi.org/10.1155/2018/9521086

Greenhalgh T, Knight M, A'Court C et al (2020) Management of postacute covid-19 in primary care. BMJ 370:m3026. https://doi.org/ 10.1136/bmj.m3026

Guvener O (2020) Balneotherapy in the era of COVID-19: should it be recommended or not? Int J Biometeorol 1. https://doi.org/10. 1007/s00484-020-01943-8

Han E, Kim B, Im S et al (2014) Effects of adjuvant hydrotherapy on functional status and mental relaxation in patients with knee osteoarthritis: preliminary study. J Korean Geriatr Soc 18:153. https://doi.org/10.4235/jkgs.2014.18.3.153

Iwu CJ, Iwu CD, Wiysonge CS (2021) The occurrence of long COVID: a rapid review. Pan Afr Med J 38:65. https://doi.org/10.11604/ pamj.2021.38.65.27366

Jain V, Yuan J-M (2020) Predictive symptoms and comorbidities for severe COVID-19 and intensive care unit admission: a systematic review and meta-analysis. Int J Public Health 1-14. https://doi. org/10.1007/s00038-020-01390-7

Jenefer Jerrin R, Theebika S, Panneerselvam P et al (2021) Yoga and naturopathy intervention for reducing anxiety and depression of Covid-19 patients - a pilot study. Clin Epidemiol Glob Health 11:100800. https://doi.org/10.1016/j.cegh.2021.100800

Kardeş S (2021) Spa therapy (balneotherapy) for rehabilitation of survivors of COVID-19 with persistent symptoms. Med Hypotheses 146:110472. https://doi.org/10.1016/j.mehy.2020.110472

Khaltaev N, Solimene U, Vitale F, Zanasi A (2020) Balneotherapy and hydrotherapy in chronic respiratory disease. $\mathrm{J}$ Thorac Dis 12:4459-4468. https://doi.org/10.21037/jtd-gard-2019-009

Lee Y, Min P, Lee S, Kim S-W (2020) Prevalence and duration of acute loss of smell or taste in COVID-19 patients. J Korean Med Sci 35:e174. https://doi.org/10.3346/jkms.2020.35.e174

Li Z, Zheng C, Duan C, et al (2020) Rehabilitation needs of the first cohort of post-acute COVID-19 patients in Hubei, China. Eur J Phys Rehabil Med 56:339-344. https://doi.org/10.23736/S19739087.20.06298-X

Ma T, Song X, Ma Y et al (2021) The effect of thermal mineral waters on pain relief, physical function and quality of life in patients with osteoarthritis. Medicine (baltimore) 100:e24488. https://doi.org/ 10.1097/MD.0000000000024488

Maccarone MC, Masiero S (2021) Spa therapy interventions for post respiratory rehabilitation in COVID-19 subjects: does the review of recent evidence suggest a role? Environ Sci Pollut Res Int 28:46063-46066. https://doi.org/10.1007/s11356-021-15443-8

Masiero S, Maccarone MC, Magro G (2020b) Balneotherapy and human immune function in the era of COVID-19. Int J Biometeorol 64:1433-1434. https://doi.org/10.1007/s00484-020-01914-z

Masiero S, Maccarone MC, Agostini F (2020a) Health resort medicine can be a suitable setting to recover disabilities in patients tested negative for COVID-19 discharged from hospital? A challenge for the future. Int J Biometeorol 1-3. https://doi.org/10.1007/ s00484-020-01947-4

Mériade L, Rochette C (2021) Integrated care pathway for breast cancer: a relational and geographical approach. Soc Sci Med 1982, 270:113658. https://doi.org/10.1016/j.socscimed.2020.113658

Mizuno K, Tanaka M, Tajima K, et al (2010) Effects of mild-stream bathing on recovery from mental fatigue. Med Sci Monit Int Med J Exp Clin Res 16:CR8-14

Mo X, Jian W, Su Z et al (2020) Abnormal pulmonary function in COVID-19 patients at time of hospital discharge. Eur Respir J 55:2001217. https://doi.org/10.1183/13993003.01217-2020

Mooventhan A, Nivethitha L (2014) Scientific evidence-based effects of hydrotherapy on various systems of the body. North Am J Med Sci 6:199-209. https://doi.org/10.4103/1947-2714.132935

Nalbandian A, Sehgal K, Gupta A et al (2021) Post-acute COVID19 syndrome. Nat Med 27:601-615. https://doi.org/10.1038/ s41591-021-01283-z

Nguyen Ba C (2020) Eau thermale : minéralité et autres composants: thermal water: minerality and other components. Ann Dermatol Venereol 147:1S14-11S19. https://doi.org/10.1016/S01519638(20)30031-4

Ozyemisci Taskiran O, Turan Z, Tekin S, et al (2021) Physical rehabilitation in intensive care unit in acute respiratory distress syndrome patients with COVID-19. Eur J Phys Rehabil Med 57:434-442. https://doi.org/10.23736/S1973-9087.21.06551-5

Pellegrini M, Fanin D, Nowicki Y et al (2005) Effect of inhalation of thermal water on airway inflammation in chronic obstructive pulmonary disease. Respir Med 99:748-754. https://doi.org/10. 1016/j.rmed.2004.11.001

Pozzi G, Masselli E, Gobbi G et al (2021) Hydrogen sulfide inhibits TMPRSS2 in Human airway epithelial cells: implications for SARS-CoV-2 infection. Biomedicines 9:1273. https://doi.org/10. 3390/biomedicines 9091273

Puchner B, Sahanic S, Kirchmair R, et al (2021) Beneficial effects of multi-disciplinary rehabilitation in postacute COVID-19: an observational cohort study. Eur J Phys Rehabil Med 57:189-198. https://doi.org/10.23736/S1973-9087.21.06549-7

Ramirez FE, Sanchez A, Pirskanen AT (2021) Hydrothermotherapy in prevention and treatment of mild to moderate cases of COVID19. Med Hypotheses 146:110363. https://doi.org/10.1016/j.mehy. 2020.110363

Rodriguez-Blanco C, Gonzalez-Gerez JJ, Bernal-Utrera C, et al (2021) Short-Term effects of a conditioning telerehabilitation program in confined patients affected by COVID-19 in the acute phase. A pilot randomized controlled trial. Med Kaunas Lith 57:684. https://doi.org/10.3390/medicina57070684

Sagarra-Romero L, Viñas-Barros A (2020) COVID-19: Short and long-term effects of hospitalization on muscular weakness in the elderly. Int J Environ Res Public Health 17:E8715. https://doi.org/ 10.3390/ijerph17238715

Sisó-Almirall A, Brito-Zerón P, Conangla Ferrín L et al (2021) Long Covid-19: proposed primary care clinical guidelines for diagnosis and disease management. Int J Environ Res Public Health 18:4350. https://doi.org/10.3390/ijerph18084350

Steardo L, Steardo L, Verkhratsky A (2020) Psychiatric face of COVID-19. Transl Psychiatry 10:261. https://doi.org/10.1038/ s41398-020-00949-5

Sun P, Qie S, Liu Z et al (2020a) Clinical characteristics of hospitalized patients with SARS-CoV-2 infection: a single arm meta-analysis. J Med Virol 92:612-617. https://doi.org/10.1002/jmv.25735

Sun T, Guo L, Tian F et al (2020b) Rehabilitation of patients with COVID-19. Expert Rev Respir Med 14:1249-1256. https://doi. org/10.1080/17476348.2020.1811687

Tang B, Ma L, Yao X et al (2017) Hydrogen sulfide ameliorates acute lung injury induced by infrarenal aortic cross-clamping by 
inhibiting inflammation and angiopoietin 2 release. J Vasc Surg 65:501-508.e1. https://doi.org/10.1016/j.jvs.2015.10.010

Torres-Castro R, Vasconcello-Castillo L, Alsina-Restoy X et al (2021) Respiratory function in patients post-infection by COVID-19: a systematic review and meta-analysis. Pulmonology 27:328-337. https://doi.org/10.1016/j.pulmoe.2020.10.013

Torres-Ronda L, del Alcázar XS, i, (2014) The properties of water and their applications for training. J Hum Kinet 44:237-248. https:// doi.org/10.2478/hukin-2014-0129

Venkataraman T, Frieman MB (2017) The role of epidermal growth factor receptor (EGFR) signaling in SARS coronavirus-induced pulmonary fibrosis. Antiviral Res 143:142-150. https://doi.org/ 10.1016/j.antiviral.2017.03.022

Viegas J, Esteves AF, Cardoso EM et al (2019) Biological effects of thermal water-associated hydrogen sulfide on human airways and associated immune cells: implications for respiratory diseases. Front Public Health 7:128. https://doi.org/10.3389/fpubh.2019. 00128

Wang M-K, Yue H-Y, Cai J, et al (2021) COVID-19 and the digestive system: a comprehensive review. World J Clin Cases 9:37963813. https://doi.org/10.12998/wjcc.v9.i16.3796

World Health Organization (2021a) WHO Coronavirus (COVID-19) dashboard. https://covid19.who.int. Accessed 21 Oct 2021

World Health Organization (2021b) A clinical case definition of post COVID-19 condition by a Delphi consensus, 6 October 2021.
https://www.who.int/publications-detail-redirect/WHO-2019nCoV-Post_COVID-19_condition-Clinical_case_definition2021.1. Accessed 19 Oct 2021

Yang G (2020) H2S as a potential defense against COVID-19? Am J Physiol Cell Physiol 319:C244-C249. https://doi.org/10.1152/ ajpcell.00187.2020

You J, Zhang L, Ni-jia-Ti M et al (2020) Anormal pulmonary function and residual CT abnormalities in rehabilitating COVID-19 patients after discharge. J Infect 81:e150-e152. https://doi.org/10. 1016/j.jinf.2020.06.003

Zajac D (2021) Inhalations with thermal waters in respiratory diseases. J Ethnopharmacol 281:114505. https://doi.org/10.1016/j.jep.2021. 114505

Zampogna E, Paneroni M, Belli S et al (2021) Pulmonary rehabilitation in patients recovering from COVID-19. Respir Int Rev Thorac Dis 100:416-422. https://doi.org/10.1159/000514387

Zhao Z, Li Y, Zhou L et al (2021) Prevention and treatment of COVID19 using traditional Chinese medicine: a review. Phytomedicine 85:153308. https://doi.org/10.1016/j.phymed.2020.153308

Zhu X, Luo Z, Chen Y et al (2021) Tai Chi for the elderly patients with COVID-19 in recovery period. Medicine (baltimore) 100:e24111. https://doi.org/10.1097/MD.0000000000024111

\section{Authors and Affiliations}

\section{Mélina Bailly ${ }^{1}$ (D) Bertrand Evrard ${ }^{2,3} \cdot$ Emmanuel Coudeyre $^{4} \cdot$ Corinne Rochette $^{5} \cdot$ Laurent Meriade $^{5}$. Christelle Blavignac $^{6} \cdot$ Anne-Cécile Fournier $^{7} \cdot$ Yves-Jean Bignon $^{8,9} \cdot$ Frédéric Dutheil $^{10} \cdot$ Martine Duclos $^{11}$. David Thivel $^{1}$}

Bertrand Evrard

bevrard@chu-clermontferrand.fr

Emmanuel Coudeyre

ecoudeyre@chu-clermontferrand.fr

Corinne Rochette

corinne.rochette@uca.fr

Laurent Meriade

laurent.meriade@uca.fr

Christelle Blavignac

christelle.blavignac@uca.fr

Anne-Cécile Fournier

ac.fournier@innovatherm.fr

Yves-Jean Bignon

yves-jean.bignon@clermont.unicancer.fr

Frédéric Dutheil

fdutheil@chu-clermontferrand.fr

Martine Duclos

mduclos@chu-clermontferrand.fr

David Thivel

david.thivel@uca.fr

1 Université Clermont Auvergne, CRNH, AME2P, F-63000 Clermont-Ferrand, France

2 CHU Clermont-Ferrand, Service d'Immunologie, $\mathrm{CHU}$ Gabriel-Montpied, Clermont-Ferrand, France
3 Université Clermont Auvergne, INRA, UMR 1019, Clermont-Ferrand, France

4 Service de Médecine Physique Et de Réadaptation, INRAE, UNH, CHU Clermont-Ferrand, Université Clermont Auvergne, 63000 Clermont-Ferrand, France

5 Université Clermont Auvergne, Health and Terrirory Chair, CleRMa, 63000 Clermont-Ferrand, France

6 Centre Imagerie Cellulaire Santé, Université Clermont Auvergne, Clermont-Ferrand, France

7 Cluster Auvergne-Rhône-Alpes Innovation Innovatherm, 63000 Clermont-Ferrand, France

8 Université Clermont Auvergne, INSERM, U1240 Imagerie Moléculaire et Stratégies Théranostiques, Clermont-Ferrand, France

9 Département d'Oncogénétique, Centre Jean Perrin, Clermont-Ferrand, France

10 Preventive and Occupational Medicine, Université Clermont Auvergne, CNRS, LaPSCo, Physiological and Psychosocial Stress, CHU Clermont-Ferrand, University Hospital of Clermont-Ferrand, Witty Fit, 63000 Clermont-Ferrand, France

11 Service de Médecine du Sport Et Des Explorations Fonctionnelles, CHU de Clermont-Ferrand, Université Clermont Auvergne, INRA, UNH, Unité de Nutrition Humaine, CRNH Auvergne, Clermont-Ferrand, France 